\title{
Enhancement of the Pitting Corrosion Resistance of AISI 316LVM Steel with Ta-Hf-C/Au Bilayers for Biomedical Applications
}

\author{
Pablo Guzmán, ${ }^{1}$ Willian Aperador, ${ }^{1}$ and Luis Yate $^{2}$ \\ ${ }^{1}$ School of Engineering, Universidad Militar Nueva Granada, Carrera 11, No. 101-80, 49300 Bogotá, Colombia \\ ${ }^{2}$ CIC biomaGUNE, Paseo Miramón 182, 20009 Donostia, Spain \\ Correspondence should be addressed to Luis Yate; lyate@cicbiomagune.es
}

Received 16 October 2016; Revised 13 December 2016; Accepted 29 December 2016; Published 17 January 2017

Academic Editor: Albano Cavaleiro

Copyright (C) 2017 Pablo Guzmán et al. This is an open access article distributed under the Creative Commons Attribution License, which permits unrestricted use, distribution, and reproduction in any medium, provided the original work is properly cited.

Tantalum carbide $(\mathrm{TaC})$, hafnium carbide (HfC), and Ta-Hf-C mixed coatings with and without a gold (Au) interlayer were deposited on 316LVM steel substrates by the magnetron cosputtering technique in order to improve the corrosion resistance of steel substrates in a simulated biological fluid. To study the effect of the gold interlayer on pitting corrosion, the different systems were placed in contact with Ringer's solution at $\mathrm{pH} 7.4$ and a temperature of $37^{\circ} \mathrm{C}$. The electrochemical properties of the coatings were determined using polarization curves. Subsequently, the surface morphologies were observed using scanning electron microscopy (SEM) in order to analyze the corrosion processes on the different surfaces. The gold interlayer was found to significantly improve the electrochemical properties of the system, showing a decrease in the pitting corrosion and deterioration rate, while it is expected that the binary and ternary carbides provide mechanical stability to the bilayers protecting the gold.

\section{Introduction}

The constantly evolving human body is a biological system that responds to stimuli and reaches a state of homeostasis [1$3]$, in which all organs and tissues are maintained in equilibrium with the performance of the system. The internal environmental variables of the body, including temperature, pressure, $\mathrm{pH}$, and ion concentration, vary following very specific behaviors to prevent any type of malfunction that could result in serious medical complications [4-7]. In addition, the body identifies foreign agents, which are subsequently attacked by the immune system to maintain the internal balance of the system. For this reason, not just any material can be implanted into the human body because if the material does not demonstrate a set of characteristics, such as biocompatibility, good corrosion resistance, and mechanical wear resistance, the presence of the material could alter the abovementioned environmental variables and thereby cause harm, which can range from cell damage to partial damage to the organs and surroundings of the system $[8,9]$.
Over time, new materials that do not affect the performance of the human body and can thus be utilized as biomaterials, specifically in orthopedics, have been developed [1012]. Titanium and its different alloys are commonly used in prosthesis fabrication because these materials possess characteristics such as high corrosion resistance, favorable biocompatibility, and good mechanical features that allow the use of titanium in a wide range of applications [13-16]. Nevertheless, due to the increasing demand, there is an urgent need for new studies of different materials that could satisfy the current market demand $[17,18]$.

To date, materials such as $\mathrm{Ta}$ and $\mathrm{Nb}$ and their alloys and thin films have achieved high acceptance in the biomaterials field due to their good corrosion resistance and their tendency to be inert in the human body [19-24]. However, the corrosive processes that occur in the body are highly aggressive due to the high chloride ions concentration, which can contribute to accelerated degradation of biomedical implants. During accelerated degradation, some ions could be released (depending on the implant material), which could influence 
the acidification of the system and result in deterioration of the implants $[25,26]$.

Different types of corrosion, including crevice corrosion, intergranular corrosion, and pitting corrosion, can affect an implant. Pitting corrosion largely affects stainless steel that is exposed to extreme conditions, such as those found in biological fluids. Even though stainless steel is widely used in surgical instrumentation, the use of stainless steel as a permanent implant exhibits a highly degradative process that can be attributed to pitting corrosion. This phenomenon consists basically of local anodic zones that, in the presence of a constant potential and increasing current, cause the material to deteriorate, which leads to a decrease in mass, degrades the material into a hole-like shape, and results in failure of the component [17, 27]. Recently, Marciniak et al. [28] reported on the improvement of the corrosion resistance of the 316LVM stainless steel by modifying its surface with passive carbon coatings. The authors showed that the coated steel presented high resistance to pitting and crevice corrosion, besides good biocompatibility. On the other hand, Liu et al. [29] have shown that 316LVM steel stents coated with $\mathrm{TiO}_{2}$ layers presented better passivation stability and antibreakdown performance than bare stents in a phosphate buffered solution. In general, the surface modification of the 316LVM stainless steel seems to be one of the solutions to improve its corrosion resistance in physiological conditions in order to be used as human implants [30, 31].

Gold, silver, and platinum are considered noble materials because they are inert to the environment. It is difficult to generate an oxidation process on the surface of these elements. Therefore, these types of materials can be useful as protective barriers against corrosive processes and could mitigate pitting and prevent degradation of the implant $[12,15]$.

This study evaluates the corrosive behavior of $316 \mathrm{LVM}$ steel substrates with different combinations of Ta-Hf-C with and without an intermediate gold layer, which was deposited using the nonreactive magnetron sputtering technique, with the aim of improving the corrosion resistance of steel substrates in a simulated biological fluid.

\section{Experimental}

Ta-Hf-C and Ta-Hf-C/Au bilayers were deposited on silicon (100) and AISI 316LVM steel substrates through the nonreactive magnetron sputtering technique using an AJA-ATC 1800 UHV system with a base pressure of $10^{-7} \mathrm{~Pa}$. For deposition of the thin films, we used individual targets with the following conditions: diameter, $5.08 \mathrm{~cm}$; carbon (C) purity, 99.999\%; purities of the $\mathrm{Au}, \mathrm{Ta}$, and Hf targets, 99.95\%; confocal configuration; and deposition pressure of $0.4 \mathrm{~Pa}$ of pure argon.

The gold films, which have a thickness of approximately $0.8 \mu \mathrm{m}$, were deposited at room temperature with substrate rotation of $80 \mathrm{rpm}$ for 20 minutes and an applied direct current (DC) power of $150 \mathrm{~W}$ to the gold target. Prior to the deposition of the films, the substrates were cleaned with ethanol and then with plasma at a radio frequency $(\mathrm{RF})$ power of $25 \mathrm{~W}$ and a pure argon pressure of $4 \mathrm{~Pa}$ for 10 minutes. To improve the adhesion of the gold films, a metallic layer of TaHf with a thickness of approximately $20 \mathrm{~nm}$ was deposited between the gold and the stainless steel by applying RF power of $100 \mathrm{~W}$ to each Ta and Hf target.

Finally, Ta-Hf-C films with different thicknesses and compositions were deposited by varying the RF power applied to the Ta and Hf targets $(100 \mathrm{~W}-0 \mathrm{~W}, 70 \mathrm{~W}-30 \mathrm{~W}$, $30 \mathrm{~W}-70 \mathrm{~W}$, and $0 \mathrm{~W}-100 \mathrm{~W}$, resp.) and maintaining the $\mathrm{DC}$ power in the carbon target fixed at $380 \mathrm{~W}$. The Ta-Hf-C thin films were deposited at a substrate temperature of $300^{\circ} \mathrm{C}$ with a negative bias RF voltage of $50 \mathrm{~V}$ and at a target-substrate distance of $15 \mathrm{~cm}$; the deposition time for the Ta-Hf-C films was 2 hours.

The coating thickness and cross-sectional morphology were determined using a scanning electron microscope (SEM; JEOL JSM-6490LV). A Zeiss Sigma Family field emission SEM was used for the corrosion and energy dispersive $\mathrm{X}$-ray spectroscopy (EDS) analyses.

After short etching of the sample surface with Ar+ ions at an energy of $3 \mathrm{kV}$ to remove contamination, X-ray photoelectron spectroscopy (XPS) analyses were performed using a SAGE HR100 (SPECS) with a nonmonochromatic source $(\mathrm{Mg} \mathrm{K} \alpha 1253.6 \mathrm{eV})$.

To evaluate the corrosion resistance under static conditions, a potentiostat was used with the Tafel technique (Reference $600^{\mathrm{TM}}$, Gamry Instruments Inc.). These tests were performed at a temperature of $37 \pm 0.2^{\circ} \mathrm{C}$ using Ringer's balanced salt solution as an electrolyte to simulate the physiological conditions of the human body and at $\mathrm{pH}$ of 7.4. The assembly consisted of a composite cell with a platinum counter electrode, an $\mathrm{Ag} / \mathrm{AgCl}$ reference electrode, and the coated specimens with an exposed area of $1 \mathrm{~cm}^{2}$ as working electrodes. The polarization curves were measured after 1 hour of immersion with a sweep rate of $1 \mathrm{mV} / \mathrm{s}$ and at a voltage range from $-250 \mathrm{mV}$ to $+1250 \mathrm{mV}$ with respect to the corrosion potential $\left(E_{\text {corr }}\right)$. These curves allow the calculation of the chemical reactivity and corrosion rate of each of the coatings. The values of the corrosion rate $\left(V_{\text {corr }}\right)$ were calculated from the Tafel slopes, and the corrosion current density $\left(I_{\text {corr }}\right)$ values in the potential range of $\pm 250 \mathrm{mV}$ with respect to $E_{\text {corr }}$ were calculated from the anodic polarization curves.

\section{Results and Discussion}

3.1. Cross-Sectional Scanning Electron Microscopy (SEM). Figure 1 shows the cross section of the different Ta-Hf-C/Au bilayers deposited onto silicon substrates. The images show that the Au films exhibit a very dense structure with a planar surface and no discontinuities between the interfaces of the Au film, the Ta-Hf metallic adhesion layer, and the Si substrate. However, the Ta-Hf-C coatings show a clear columnar structure with some cracks between the coatings and the $\mathrm{Au}$ film, indicating the low affinity of gold for the carbides. This columnar structure has been observed recently by Lasfargues et al. [32] for $\mathrm{HfC}$ and $\mathrm{TaC}$ coatings with different carbon contents and seems to be inherent to the carbide structure.

The thicknesses of the Ta-Hf-C coatings were determined from the cross-sectional SEM images and are listed in Table 1. The $\mathrm{TaC}$ films are slightly thicker due to the higher sputtering yield of tantalum compared with that of hafnium [33]. 
TABLE 1: RF applied power to the Ta and Hf targets and the thicknesses and TaC and HfC phase contents determined through XPS analyses.

\begin{tabular}{lccccc}
\hline Sample & RF power, Ta target $(\mathrm{W})$ & RF power, Hf target $(\mathrm{W})$ & Thickness $(\mu \mathrm{m})$ & TaC at.\% & HfC at.\% \\
\hline TaC & 100 & 0 & 1.6 & 100 & 7.1 \\
$70 \mathrm{TaC}-30 \mathrm{HfC}$ & 70 & 30 & 70 & 1.1 & 25 \\
$30 \mathrm{TaC}-70 \mathrm{HfC}$ & 30 & 100 & 1.4 & 21 & 0 \\
$\mathrm{HfC}$ & 0 & & 79 & 100 \\
\hline
\end{tabular}

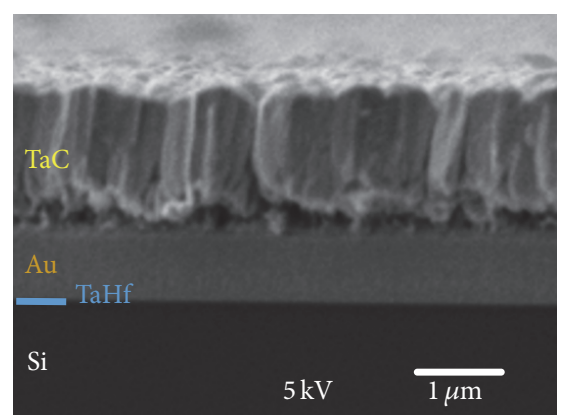

(a)

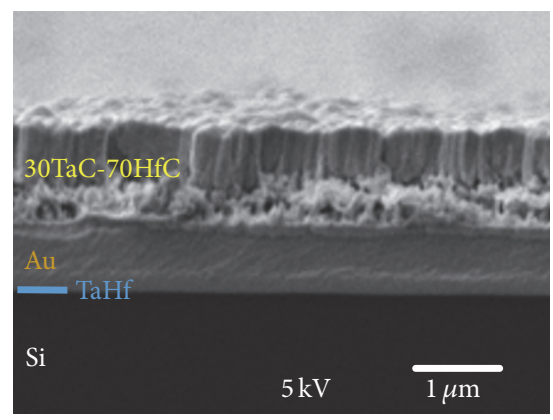

(c)

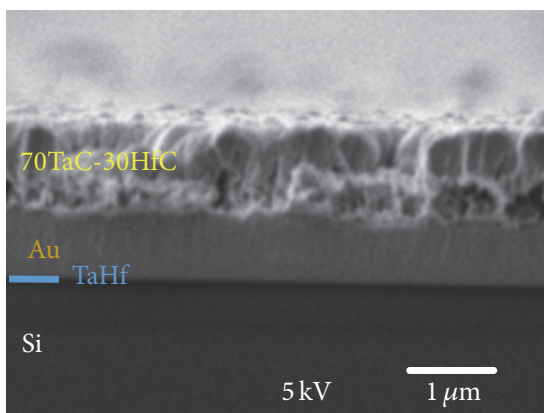

(b)

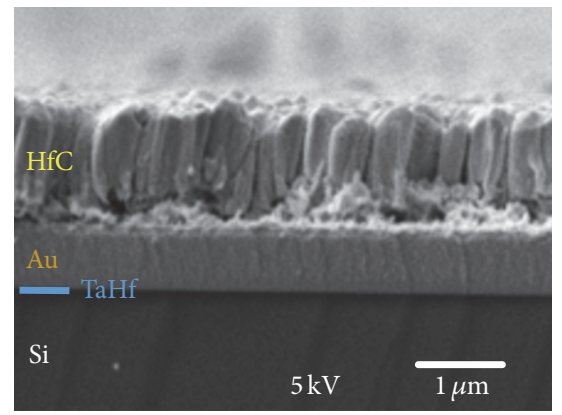

(d)

FIGURE 1: Cross-sectional SEM images of the as-coated samples showing the Au intermediate layer with the different Ta-Hf-C coatings: (a) TaC, (b) 70TaC-30HfC, (c) 30TaC-70HfC, and (d) HfC.

3.2. X-Ray Photoelectron Spectroscopy (XPS). Figure 2 shows the XPS Ta $4 \mathrm{f}$ and Hf $4 \mathrm{f}$ spectra of the TaC, HfC, and TaHf-C mixture samples. The main Ta $4 f_{7 / 2}$ and $\mathrm{Hf} 4 \mathrm{f}_{7 / 2}$ peak positions are located at approximately 23.3 and $14.8 \mathrm{eV}$ and can be attributed to $\mathrm{TaC}$ [34] and $\mathrm{HfC}$ [33] carbide bonds, confirming the presence of carbides in their pure form. From the area of the photoelectron peaks, it was also possible to estimate the $\mathrm{TaC}$ and $\mathrm{HfC}$ phase contents in the mixture samples, and these values, which are listed in Table 1, demonstrate that the TaC and HfC contents are almost correlated to the RF power applied to the Ta and Hf targets. This indicates that the chemical composition of the samples can be easily controlled by adjusting the deposition parameters.

3.3. Corrosion Studies. Figure 3 shows the potentiodynamic polarization curves of the different samples. In general, the corrosion processes were established to maintain the stability of the carbide layers in zone II, where many localized corrosion phenomena (pitting) occurred in the system without the gold interlayer; the analyses of the samples with the

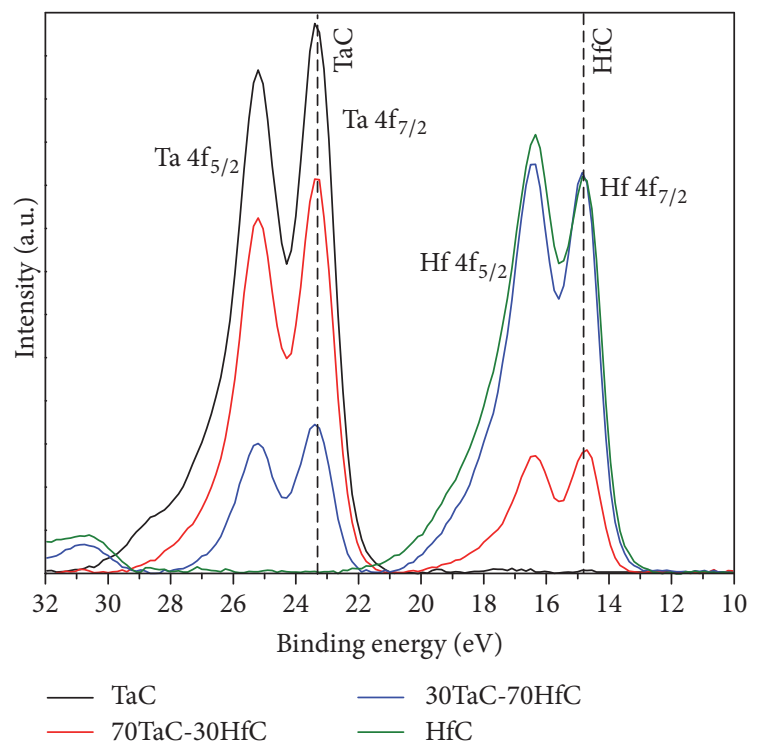

FIGURE 2: High resolution XPS spectra of the different samples. 


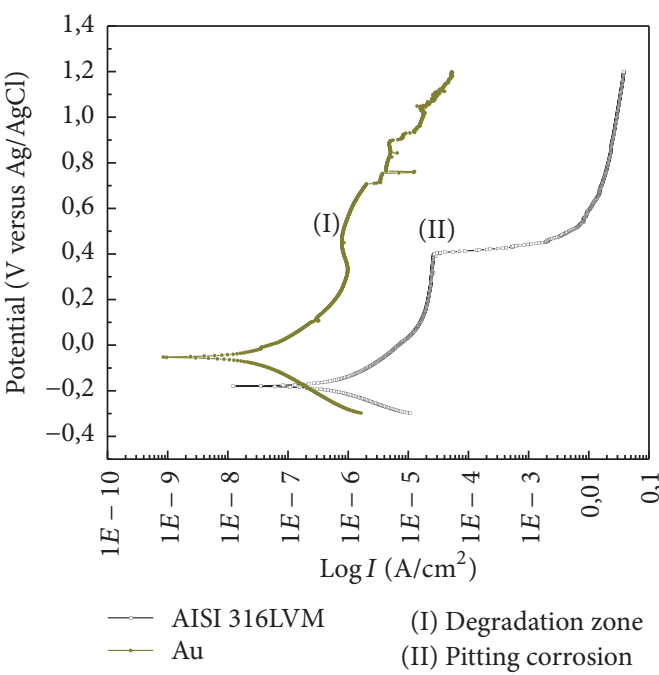

(a)

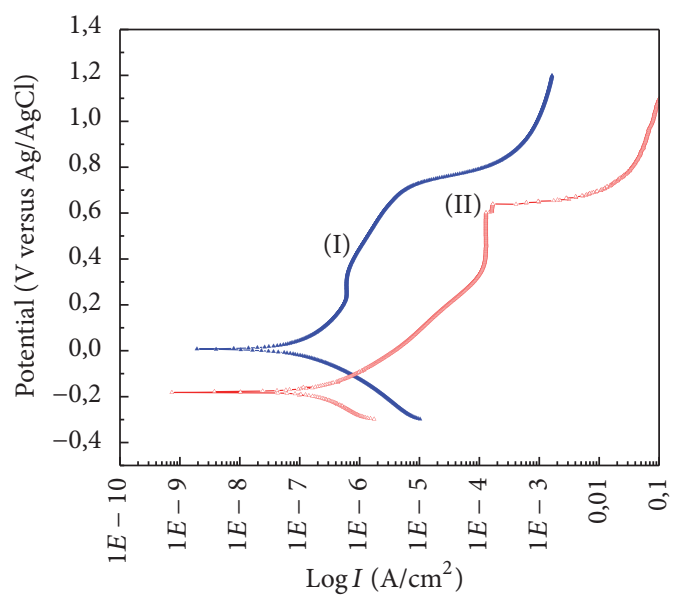

$\begin{array}{ll}\mathrm{HfC} \text { with gold layer } & \text { (I) Degradation zone }\end{array}$ - - HfC without gold layer (II) Pitting corrosion

(c)

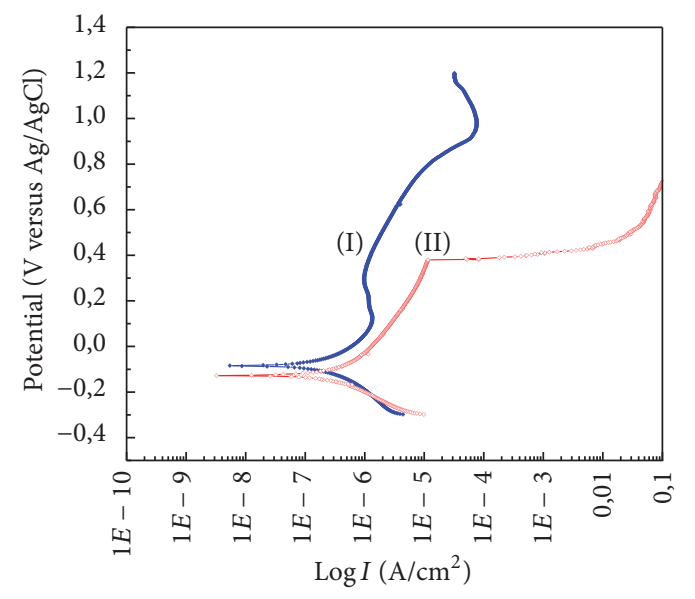

- $\mathrm{TaC}$ with gold layer $\mathrm{TaC}$ without gold layer

(I) Degradation zone (II) Pitting corrosion

(b)

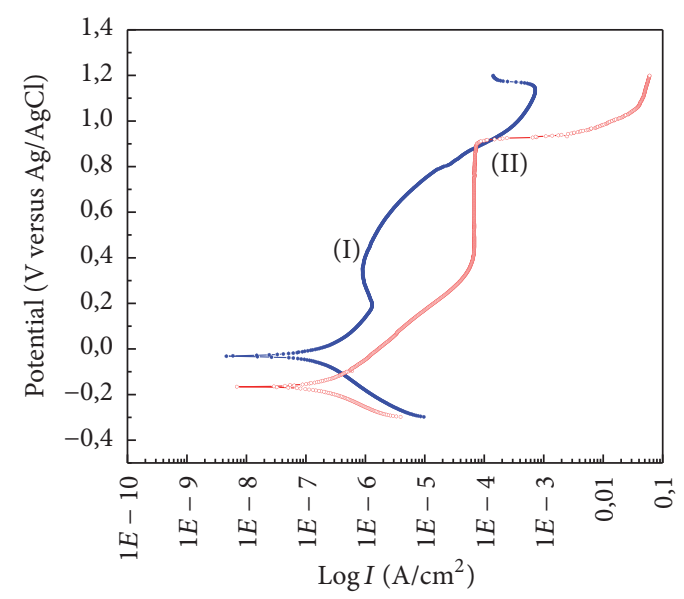

- $30 \mathrm{TaC}-70 \mathrm{HfC}$ with gold layer $\quad$ (I) Degradation zone $-30 \mathrm{TaC}-70 \mathrm{HfC}$ without gold layer (II) Pitting corrosion

(d)

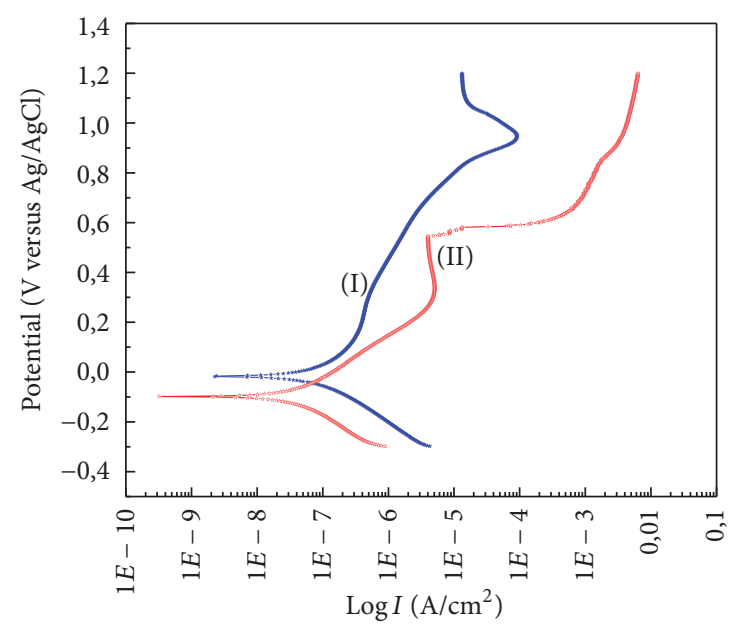

- 70TaC-30HfC with gold layer

(I) Degradation zone

$-70 \mathrm{TaC}-30 \mathrm{HfC}$ without gold layer

(II) Pitting corrosion

(e)

FIGURE 3: Polarization curves of the coatings with and without the gold interlayer. (a) Steel and gold, (b) TaC with and without the gold layer, (c) $\mathrm{HfC}$ with and without the gold layer, (d) mixture of $30 \mathrm{TaC}$ and $70 \mathrm{HfC}$ with and without the gold layer, and (e) mixture of $70 \mathrm{TaC}$ and $30 \mathrm{HfC}$ with and without the gold layer. 
TABLE 2: Chemical composition of the 316LVM stainless steel.

\begin{tabular}{lccccccc}
\hline $\mathrm{Fe}$ & $\mathrm{Cr}$ & $\mathrm{Ni}$ & $\mathrm{Mo}$ & $\mathrm{Mn}$ & $\mathrm{Si}$ & $\mathrm{S}$ & \\
\hline $61.79 \%$ & $18.9 \%$ & $13.2 \%$ & $3.6 \%$ & $1.7 \%$ & $0.75 \%$ & $0.03 \%$ & $0.03 \%$ \\
\hline
\end{tabular}

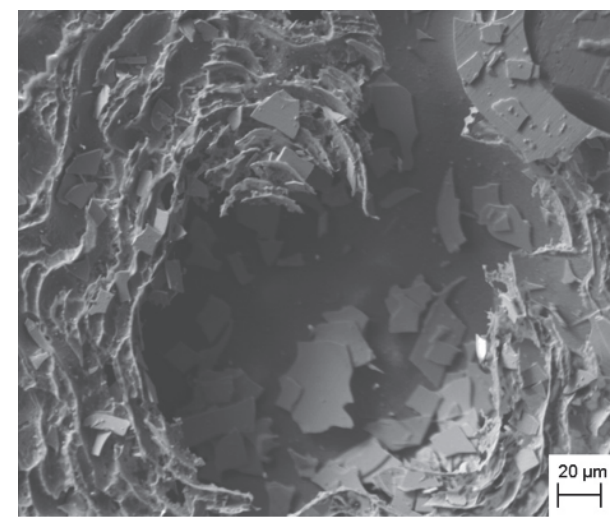

(a)

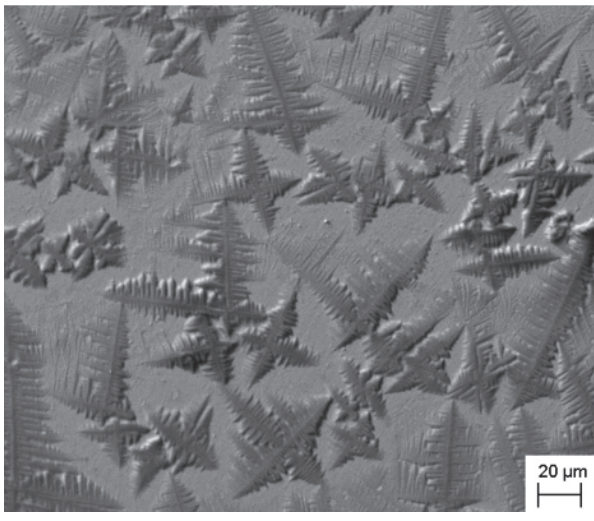

(c)

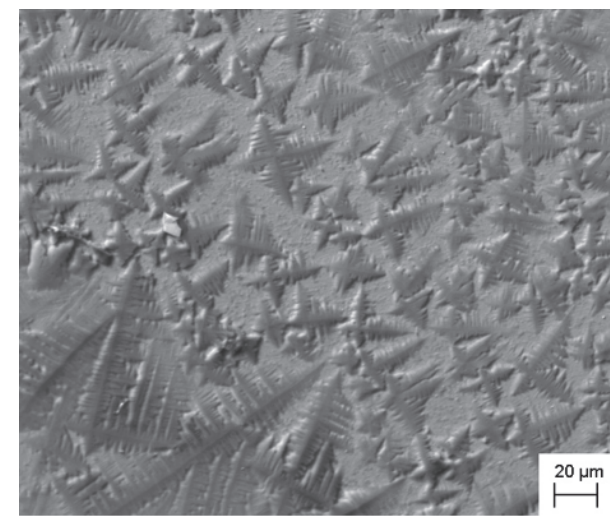

(b)

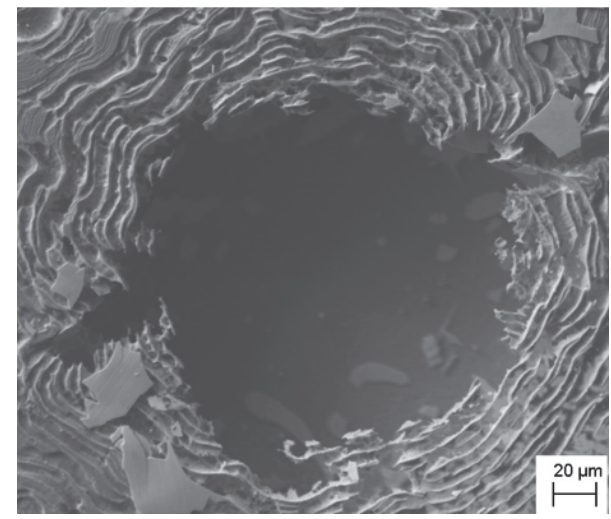

(d)

FigurE 4: SEM micrographs of the different samples after the corrosive attack: (a) TaC, (b) HfC, (c) 30TaC-70HfC, and (d) 70TaC-30HfC.

interlayer show that this interlayer acts as a protective layer that dissolves at a regular rate in zone I.

316LVM steel presents poor corrosion resistance due to chlorine (pitting corrosion) because the attack is localized in a reduced area, which deepens at a rapid pace, causing an increase in the current density at a constant potential. The chemical composition of the 316LVM stainless steel is shown in Table 2. It is well known that steel with a high content of $\mathrm{Cr}$, as in this case, could help to create a passive layer that protects the steel from pitting corrosion. Nevertheless, in the presence of Ringer's Lactate saline solution, the formation of these layers is less favored, and therefore the pitting corrosion occurs. This type of attack occurs only on materials that work at a potential (corrosion potential, $E_{\text {corr }}$ ) higher than a certain critical value, which is known as the pitting potential $\left(E_{\text {pit }}\right)$ and depends on the composition of the metallic material. The behaviors of the coatings show a barrier effect; as a result, the corrosion processes were decreased in the samples, and the corrosion potential increased in proportion to the amount of carbides in the mixture. In other words, protective layers were formed on the material, making the corrosion potential more positive.

The samples without a gold interlayer exhibited a different behavior in the passive layer, resulting in a markedly lower pitting corrosion potential and thereby generating a steady growth of pits on the material surface, as can be seen in the SEM images in Figure 4. The maximum potentials at which the coating can operate without propagating the phenomena to the entire surface are the following: for $\mathrm{TaC}, 0.38 \mathrm{~V}$ versus $\mathrm{Ag} / \mathrm{AgCl}$; for $\mathrm{HfC}, 0.63 \mathrm{~V}$ versus $\mathrm{Ag} / \mathrm{AgCl}$; for $70 \mathrm{TaC}-30 \mathrm{HfC}$, $0.58 \mathrm{~V}$ versus $\mathrm{Ag} / \mathrm{AgCl}$; for $30 \mathrm{TaC}-70 \mathrm{HfC}, 0.92 \mathrm{~V}$ versus $\mathrm{Ag} / \mathrm{AgCl}$. The dissimilar behavior of the carbides is caused principally by the difference in potentials among them. As a result, $\mathrm{HfC}$ is electrochemically less reactive in the corrosive process than $\mathrm{TaC}$; thus, in the combinations, $\mathrm{HfC}$ works as a cathode, and the surrounding $\mathrm{TaC}$ dissolves and works as an anode.

The corrosion current, corrosion potential, and corrosion rates are listed in Table 3, while Figure 5 shows the corrosion potentials of the bilayers and the corresponding values of the 
TABLE 3: Corrosion parameters obtained from the Tafel analyses for the 316LVM stainless steel substrate, the gold layer, and the Ta-Hf-C/Au bilayers.

\begin{tabular}{lccc}
\hline Sample & $I_{\text {corr }}\left(\mathrm{nA} / \mathrm{cm}^{2}\right)$ & $E_{\text {corr }}(\mathrm{mV}$ versus $\mathrm{Ag} / \mathrm{AgCl})$ & Corrosion rate $\left(\cdot 10^{-3} \mathrm{~mm} / \mathrm{yr}\right)$ \\
\hline $316 \mathrm{LVM}$ & 840.7 & -180.0 & 22.37 \\
$\mathrm{Au}$ & 40.4 & -53.0 & 1.07 \\
$\mathrm{HfC} / \mathrm{Au}$ & 130.0 & 7.32 & 3.47 \\
$\mathrm{TaC} / \mathrm{Au}$ & 462.0 & -84.6 & 12.30 \\
$30 \mathrm{TaC}-70 \mathrm{HfC} / \mathrm{Au}$ & 417.0 & -30.9 & 11.10 \\
$70 \mathrm{TaC}-30 \mathrm{HfC} / \mathrm{Au}$ & 176.0 & -17.1 & 4.69 \\
\hline
\end{tabular}

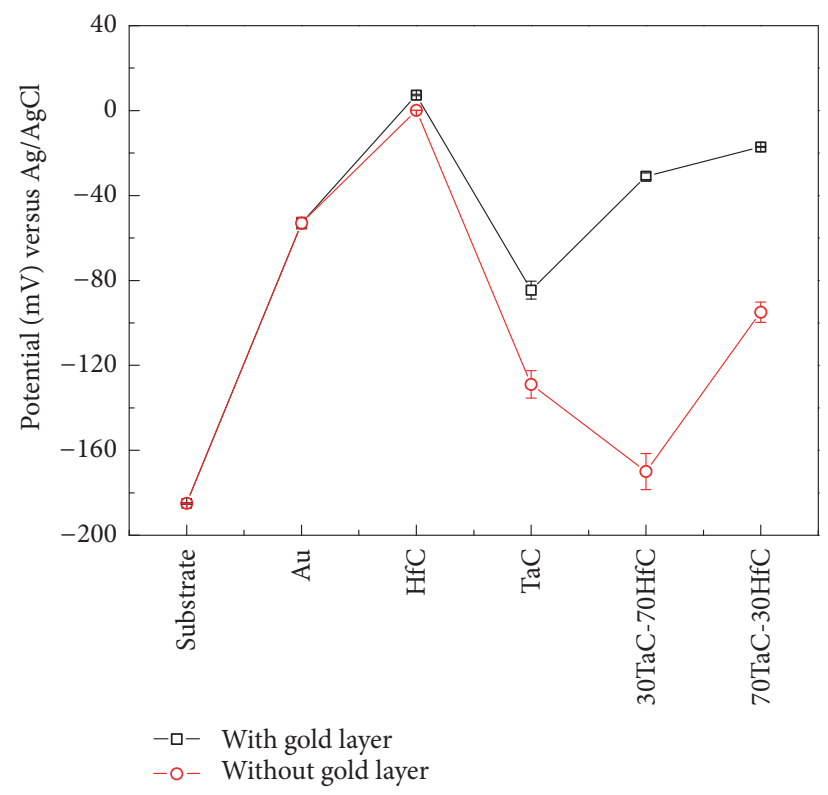

FIGURE 5: Comparison of different potentials obtained for samples with and without the gold interlayer.

pure gold, steel substrate, and individual Ta-Hf-C layers. As illustrated, in all cases, the bilayer samples presented higher potentials than the Ta-Hf-C layers without the Au interlayer. The HfC showed the noblest potential among the samples and thus the greatest protection, whereas, as expected, the steel substrate presented the worst corrosion behavior. This better corrosion resistance in the $\mathrm{HfC}$ carbide, compared to the $\mathrm{TaC}$, can be attributed to a higher structural stability, as recently reported by Lasfargues et al. [32]. However, the comparison of the $30 \mathrm{TaC}-70 \mathrm{HfC}$ and $70 \mathrm{TaC}-30 \mathrm{HfC}$ samples revealed that the sample with the highest percentage of Ta exhibited a better potential because the addition of $\mathrm{HfC}$ improves the response to corrosive processes, and this result is attributed to the better performance of the HfC sample. Nevertheless, the addition of Ta to the sample with the highest percentage of Hf considerably decreased the corrosion resistance, demonstrating that even though $\mathrm{Ta}$ is a good alloying agent when the system presents good resistance to corrosion, the addition can cause a decrease in the response of the sample to corrosive processes.

As shown in Figure 6, which illustrates the corrosion rates of all the samples, all of the bilayer samples with the gold

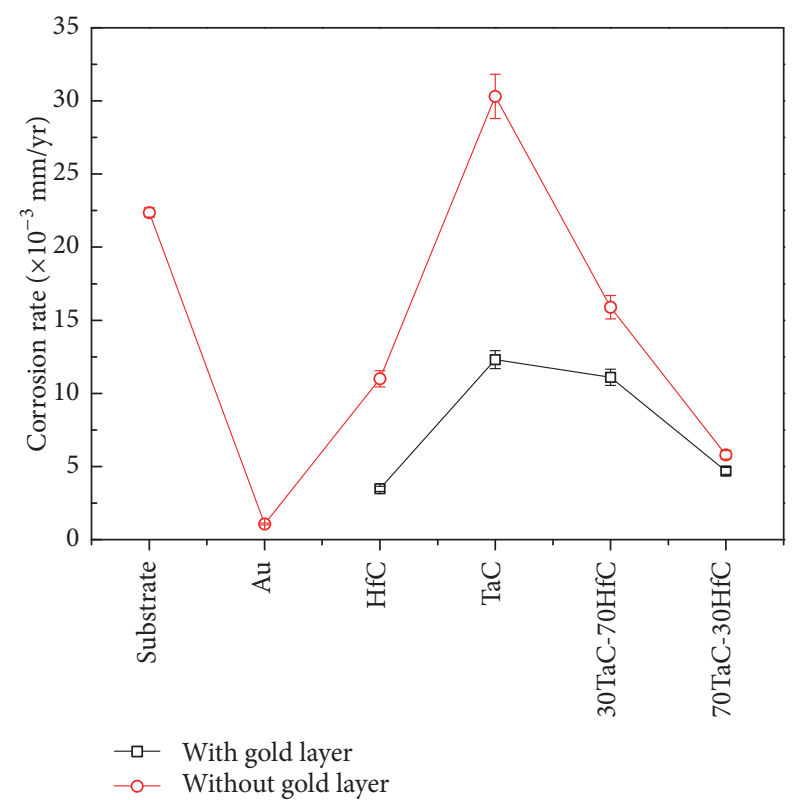

FIGURE 6: Corrosion rate for all the systems with and without the interlayer of gold.

interlayer show improved corrosion resistance compared with the corresponding $\mathrm{TaC}$, HfC, and Ta-Hf-C samples without the gold interlayer. Additionally, none of the bilayer samples showed pitting corrosion when exposed to Ringer's solution. This result is attributed to a reduction in the electrochemical potential due to the presence of the Au interlayer, which decreases the potential difference between the substrate and the coating. It is worth noting that all the bilayer samples showed a higher corrosion rate than the pure Au film, which can be explained by the formation of a heterogeneous structure in the gold-carbide interface. A similar behavior has been previously reported for the addition of $\mathrm{Au}$ and $\mathrm{Pd}$ in CoCr-based alloys which led to a significant decrease in the corrosion resistance compared to pure $\mathrm{CoCr}$ alloys due to the formation of heterogeneous precipitates [35].

The gold interlayer improves the corrosion resistance, even though the stability of the material depends strongly on the protective carbide layer. Nevertheless, it constitutes an appropriate system for improving corrosion resistance (pitting corrosion) in Ringer's solution because, in every case tested, the resistance to a localized attack was decreased due to the nonreactive nature of the material. Therefore, the 


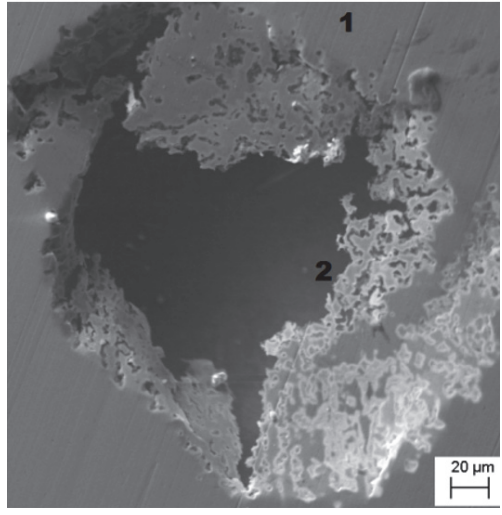

(a)

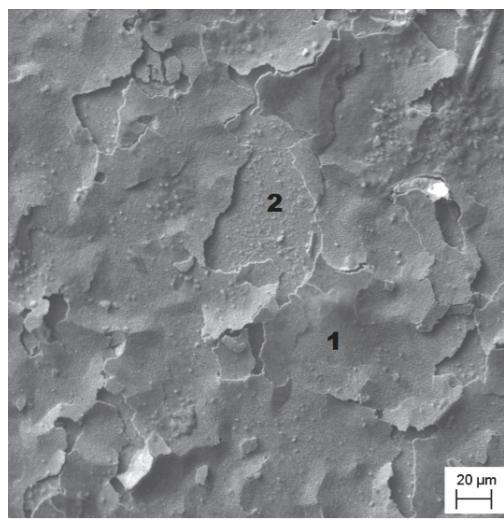

(d)

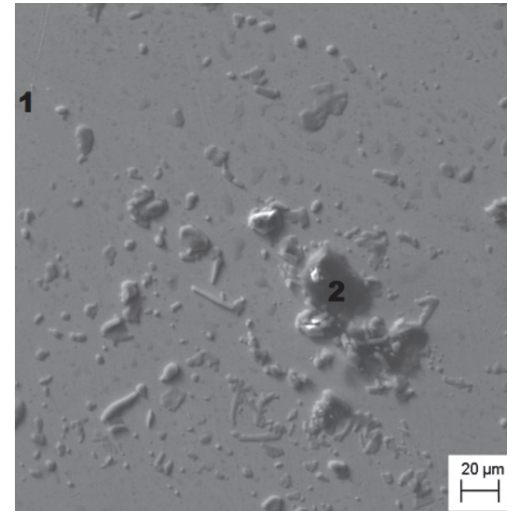

(b)

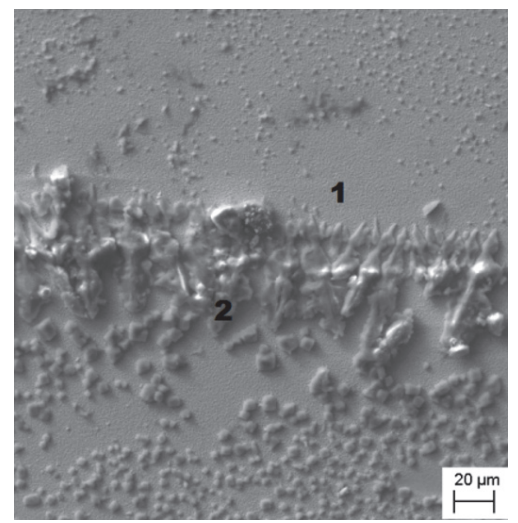

(e)

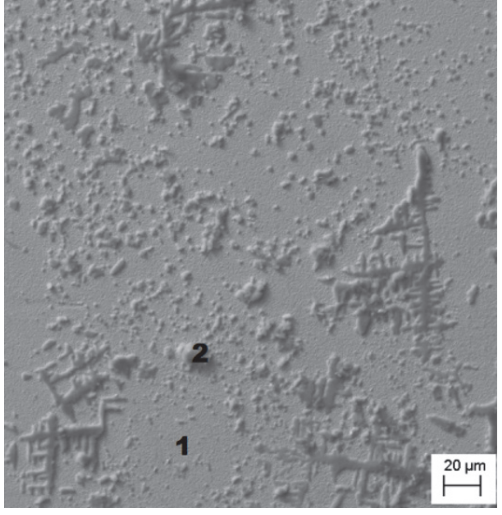

(c)

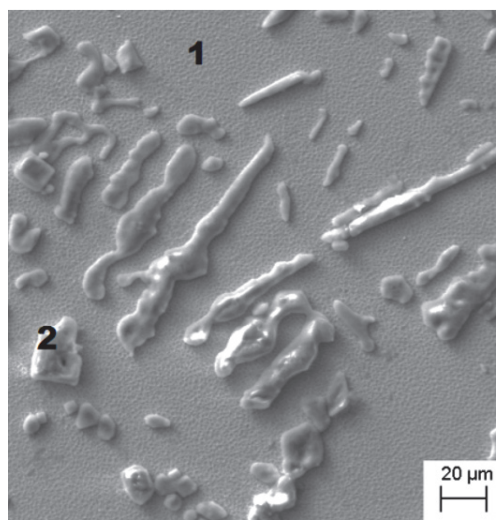

(f)

FIGURE 7: SEM micrographs of the different samples after the corrosive attack: (a) 316LVM steel, (b) Au, (c) TaC/Au, (d) HfC/Au, (e) 30 TaC$70 \mathrm{HfC} / \mathrm{Au}$, and (f) $70 \mathrm{TaC}-30 \mathrm{HfC} / \mathrm{Au}$. The numbers show the points where the EDS analyses were performed.

coatings present higher resistance to corrosion in a solution with chloride ions.

The Au layer itself has a homogeneous structure free of pores, which allows protection of the substrate, improves the corrosion potentials, and makes these coatings an interesting case study for possible application as a biomaterial. However, $\mathrm{Au}$ and steel have very different corrosion potentials. If the $\mathrm{Au}$ surface shows damage or imperfections due to its low hardness, the steel is left exposed, forming a galvanic corrosion cell that intensifies the pitting corrosion. In the samples with Ta-Hf-C/Au bilayers, the good mechanical and tribological properties of the carbide layer [36] are expected to protect the Au interlayer.

3.4. SEM after Electrochemical Tests. As a natural response of the AISI 316LVM stainless steel in a saline solution of $8 \mathrm{~g} / \mathrm{L} \mathrm{NaCl}$, the typical phenomenon of pitting corrosion was observed through surface characterization after 1 hour of immersion. The micrograph in Figure 7 (a) shows localized deterioration due to the generation of anodic zones, which indicates superficial pitting, corroborating the presence of a constant potential with a current increase in the anodic zone of the potentiodynamic polarization curve as was previously shown. To perform a better analysis of the area of interest, measurements using EDS were performed on two different points to obtain further information regarding the phenomena occurring on the surface of the material. After the corrosive attack, a significant decrease in iron and chromium and an increase in oxygen in point 2 are observed, when compared to point 1 (Table 4 ). This indicates the degradation processes of surface oxidation and correlates with increased levels of oxygen in areas where the deterioration is still occurring. Similarly, a high C percentage was found in the 316LVM steel which can be attributed to atmospheric contamination when the sample was exposed to air.

The gold surface, on the other hand, showed a homogenous surface without deterioration caused by the corrosive processes, as observed in Figure 7(b). A high content of oxygen in point 1 was demonstrated by EDS and is related to a chemical oxidation-reduction response in which the gold presents more positive potentials compared with other elements due to its noble behavior, making the reaction process with oxygen more difficult and thereby allowing its accumulation on the surface. In addition, dissolution induced by lactate particles in Ringer's solution on the surface of the material can be observed, and this process can be attributed to the presence of elements such as sodium, potassium, chlorine, and calcium, as detailed in Table 4. For the measurements in point 2, the EDS analysis showed high levels of sodium and chlorine. Moreover, oxygen and gold show a considerable 
TABLE 4: Atomic percentages obtained by EDS.

\begin{tabular}{|c|c|c|c|c|c|c|c|c|c|c|c|c|}
\hline \multirow{2}{*}{ Elements } & \multicolumn{2}{|c|}{$316 \mathrm{LVM}$} & \multicolumn{2}{|c|}{$\mathrm{Au}$} & \multicolumn{2}{|c|}{$\mathrm{TaC}$} & \multicolumn{2}{|c|}{$\mathrm{HfC}$} & \multicolumn{2}{|c|}{$30 \mathrm{TaC}-70 \mathrm{HfC}$} & \multicolumn{2}{|c|}{ 70TaC-30HfC } \\
\hline & Zone 1 & Zone 2 & Zone 1 & Zone 2 & Zone 1 & Zone 2 & Zone 1 & Zone 2 & Zone 1 & Zone 2 & Zone 1 & Zone 2 \\
\hline $\mathrm{C}$ & 15.4 & 18.6 & - & - & 45.2 & - & 41.8 & 33.6 & - & - & - & - \\
\hline $\mathrm{O}$ & 3.0 & 5.8 & 48.8 & 8.3 & 6.8 & 9.2 & 20.7 & 15.9 & 15.6 & 22.4 & 17.7 & - \\
\hline $\mathrm{Si}$ & 1.1 & 1.0 & - & 0.7 & - & - & - & - & - & - & - & - \\
\hline $\mathrm{Cl}$ & 0.5 & 1.2 & 1.6 & 43.9 & 12.2 & 37.9 & 5.5 & 2.3 & 33.2 & 15.0 & 31.8 & 60.2 \\
\hline $\mathrm{Cr}$ & 16.6 & 14.6 & 0.7 & - & - & - & 0.7 & 1.4 & 0.7 & - & - & - \\
\hline $\mathrm{Mn}$ & 1.3 & 1.2 & - & - & - & - & - & - & - & - & - & - \\
\hline $\mathrm{Fe}$ & 55.0 & 49.3 & - & - & - & - & - & - & - & - & - & - \\
\hline $\mathrm{Ni}$ & 5.8 & 5.2 & - & - & - & - & - & - & - & - & - & - \\
\hline $\mathrm{Cu}$ & 0.9 & 2.8 & - & - & - & - & - & - & - & - & - & - \\
\hline $\mathrm{Na}$ & - & - & 11.5 & 44.1 & 10.6 & 37.3 & 3.9 & 1.7 & 23.4 & 18.6 & 22.8 & 39.6 \\
\hline K & - & - & 1.8 & - & - & 0.5 & - & - & - & - & - & - \\
\hline $\mathrm{Ca}$ & - & - & 4.1 & - & - & 1.0 & - & - & - & - & - & - \\
\hline $\mathrm{Au}$ & - & - & 31.3 & 2.7 & - & - & 4.8 & 34.1 & - & 35.8 & - & - \\
\hline $\mathrm{Ta}$ & - & - & - & - & 25.1 & 13.9 & - & - & 7.0 & 1.0 & 18.6 & - \\
\hline $\mathrm{Hf}$ & - & - & - & - & - & - & 22.2 & 10.7 & 19.9 & 7.0 & 8.9 & - \\
\hline Total & & & & & & & & & & & & \\
\hline
\end{tabular}

decrease compared to point 1 , indicating the dissolution of solid particles in the analyzed surface. A correlation based on the topography of the surface and the polarization curves demonstrates that the gold film functions as a protective barrier to mitigate pitting corrosion and allows only active dissolution in the anodic form of the curvature and particles on the surface.

The behavior observed in the $\mathrm{TaC} / \mathrm{Au}$ sample was similar to that exhibited by the Au film, with a homogeneous surface with no signs of damage caused by corrosive processes but higher dissolution of particles, as demonstrated in Figure 7 (c). The correlation of the polarization curves with the micrograph revealed that a greater amount of particle dissolution in the surface would cause a higher corrosion rate, generating faster degradation of the coating. The EDS analysis of point 1 shows a high content of $\mathrm{Ta}$ followed by $\mathrm{C}, \mathrm{Cl}, \mathrm{Na}$, and $\mathrm{O}$, as detailed in Table 4 . The high levels of $\mathrm{C}$ might be related to the deposition of the carbides and the migration of $\mathrm{C}$ atoms to the surface. The EDS analysis in point 2 revealed the composition of the particles found on the surface and confirmed the presence of $\mathrm{Au}$ due to degradation of the Ta film. However, the gold interlayer or the substrate signals were not detected, and the results revealed only elements such as $\mathrm{Na}$, $\mathrm{Ca}, \mathrm{K}$, and $\mathrm{Cl}$ corresponding to the solution, which presented considerable increases with respect to measurements on point 1 and a decrease in the percentage of atomic Ta.

The micrograph obtained after the corrosion tests in the $\mathrm{HfC} / \mathrm{Au}$ sample showed intense surface degradation, as shown in Figure 7(d). The coating shows evidence of microcracking, and, at certain points, partial dissolution of the thin film was perceived. The correlation of the polarization curves showed that the coating exhibits a tendency to undergo pitting. However, due to the presence of the Au interlayer, the degradation continued homogeneously. Even in the presence of severe surface damage due to the corrosion process, the degradation rate of this sample was the best after the gold sample, indicating that, despite the damage caused by this phenomenon, the film with the gold layer protects the substrate, reducing degradation due to pitting corrosion. As shown in Table 4, point 1 subjected to EDS analysis shows a high presence of $\mathrm{C}, \mathrm{Hf}$, and Au corresponding to the thin film, $\mathrm{O}$ generated in oxidation processes, and $\mathrm{Na}$ and $\mathrm{Cl}$, which are present in the solution. In point 2 , a decrease in $\mathrm{C}, \mathrm{O}, \mathrm{Na}$, $\mathrm{Cl}$, and $\mathrm{Hf}$ and a considerable increase in $\mathrm{Au}$ were observed with respect to the data obtained in point 1 . This decrease can be related to dissolution of the HfC layer, which exposes the gold.

Figure 7(e) shows the micrograph obtained for the $30 \mathrm{TaC}-70 \mathrm{HfC} / \mathrm{Au}$ sample, which presents a homogeneous area without apparent damage on the surface. In general, some particles generated by the corrosion assays were observed. With the addition of $\mathrm{TaC}$, the topography does not show any of the cracking observed in the HfC sample. Nevertheless, this addition generates more negative corrosion potentials and a higher corrosion rate compared with the $\mathrm{HfC}$ sample. The results of the EDS measurements are shown in Table 4 and show the presence of $\mathrm{Hf}$ and Ta related to the thin film, $\mathrm{Na}$ and $\mathrm{Cl}$ attributed to the solution, and $\mathrm{O}$ due to redox reaction in point 1 . The analysis in point 2 suggests dissolution of the film, and this finding is corroborated by the values obtained from the EDS analysis. In addition, a large decrease in elements such as $\mathrm{Na}, \mathrm{Cl}, \mathrm{Hf}$, and Ta was observed in this case. Partial dissolution in certain areas of the $30 \mathrm{TaC}$ $70 \mathrm{HfC}$ layer was confirmed by the appearance of Au. Even with the evidence of $\mathrm{Au}, \mathrm{Cr}$ and $\mathrm{Fe}$ were not detected, which indicates improved performance against corrosive processes due to the improved electrochemical response of this system.

The SEM micrograph shown in Figure 7(f) indicates that the $70 \mathrm{TaC}-30 \mathrm{HfC} / \mathrm{Au}$ sample does not present significant damage. Additionally, the response to the corrosive process is 
evidenced in the polarization curve, and the coating presents a low corrosion rate and a potential closer to zero. The analysis in point 1 shows a high content of $\mathrm{Na}$ and $\mathrm{Cl}$ attributed to the solution. Furthermore, the presence of $\mathrm{Ta}$ and $\mathrm{Hf}$ was detected in the film, and the presence of $\mathrm{O}$ in solution and the occurrence of redox processes were evidenced. The absence of gold indicates that the corrosive processes were not sufficiently aggressive to degrade the film. The analysis in point 2 shows an increment in the content of $\mathrm{Na}$ and $\mathrm{Cl}$, suggesting that this region corresponds to a salt particle that was dissolved.

\section{Conclusions}

In this work, we successfully deposited binary and ternary Ta-Hf-C and Ta-Hf-C/Au bilayers through the magnetron cosputtering technique on AISI 316LVM steel substrates.

The electrochemical properties of the coatings were studied in Ringer's solution to simulate the physiological conditions of the human body. We found that the Au interlayers had a major effect on preventing the pitting and enhancing the corrosion resistance of the binary and ternary Ta-Hf-C layers.

The Au layer has a homogeneous structure free of pores, which provides protection to the substrate. Among the combinations of substrate/Au interlayer and the Ta-Hf-C layers, the $\mathrm{HfC} / \mathrm{Au}$ bilayer exhibited the noblest potential and the lowest corrosion rate and demonstrates its potential for biomedical applications.

\section{Competing Interests}

The authors declare no competing financial interests.

\section{Acknowledgments}

P. Guzman and W. Aperador acknowledge the support provided by Universidad Militar Nueva Granada through Project ING. 2100, financed by "Vicerrectoría de InvestigaciónesUMNG" in 2016.

\section{References}

[1] S. Ramakrishna, M. Ramalingam, T. S. S. Kumar, and W. O. Soboyejo, Biomaterials: A Nano Approach, CRC Press, Boca Raton, Fla, USA, 2010.

[2] F.-M. Chen and X. Liu, "Advancing biomaterials of human origin for tissue engineering," Progress in Polymer Science, vol. 53, pp. 86-168, 2016.

[3] R. J. Miron and D. D. Bosshardt, "OsteoMacs: key players around bone biomaterials," Biomaterials, vol. 82, pp. 1-19, 2016.

[4] D. Arcos, A. R. Boccaccini, M. Bohner et al., "The relevance of biomaterials to the prevention and treatment of osteoporosis," Acta Biomaterialia, vol. 10, no. 5, pp. 1793-1805, 2014.

[5] M. Sirova, "Assessing immunological properties of biomaterials for bone regeneration applications," in Biomaterials for Bone Regeneration, P. Dubruel and V. Vlierberghe, Eds., pp. 324-348, Elsevier, Sawston, UK, 2014.
[6] F. R. Maia, S. J. Bidarra, P. L. Granja, and C. C. Barrias, "Functionalization of biomaterials with small osteoinductive moieties," Acta Biomaterialia, vol. 9, no. 11, pp. 8773-8789, 2013.

[7] Z. Chen, T. Klein, R. Z. Murray et al., "Osteoimmunomodulation for the development of advanced bone biomaterials," Materials Today, vol. 19, no. 6, pp. 304-321, 2016.

[8] A. Sak, T. Moskalewicz, S. Zimowski et al., "Influence of polyetheretherketone coatings on the $\mathrm{Ti}-13 \mathrm{Nb}-13 \mathrm{Zr}$ titanium alloy's bio-tribological properties and corrosion resistance," Materials Science and Engineering C, vol. 63, pp. 52-61, 2016.

[9] Z. Zhou, Q. Wei, Q. Li, B. Jiang, Y. Chen, and Y. Sun, "Development of Co-based bulk metallic glasses as potential biomaterials," Materials Science and Engineering C, vol. 69, pp. 46-51, 2016.

[10] L. Yate, L. E. Coy, D. Gregurec, W. Aperador, S. E. Moya, and G. Wang, "Nb-C nanocomposite films with enhanced biocompatibility and mechanical properties for hard-tissue implant applications," ACS Applied Materials and Interfaces, vol. 7, no. 11, pp. 6351-6358, 2015.

[11] A. Esguerra-Arce, J. Esguerra-Arce, L. Yate et al., "Influence of the Al content on the: in vitro bioactivity and biocompatibility of PVD Til- xAlxN coatings for orthopaedic applications," RSC Advances, vol. 6, no. 65, pp. 60756-60764, 2016.

[12] X. Xing, H. Wang, P. Lu, and Z. Han, "Influence of rare earths on electrochemical corrosion and wear resistance of RE-Cr/Ti pack coatings on cemented 304 stainless steel," Surface and Coatings Technology, vol. 291, pp. 151-160, 2016.

[13] T. Zhou, Y. Zhu, X. Li et al., "Surface functionalization of biomaterials by radical polymerization," Progress in Materials Science, vol. 83, pp. 191-235, 2016.

[14] Y. Liu, G. Wang, H. Li, S. Pang, K. Chen, and T. Zhang, "Ti$\mathrm{Cu}-\mathrm{Zr}$-Fe-Sn-Si-Sc bulk metallic glasses with good mechanical properties for biomedical applications," Journal of Alloys and Compounds, vol. 679, pp. 341-349, 2016.

[15] S. Li, Q. Wei, Q. Li, B. Jiang, Y. Chen, and Y. Sun, "Development of Fe-based bulk metallic glasses as potential biomaterials," Materials Science and Engineering C, vol. 52, pp. 235-241, 2015.

[16] Q. Chen and G. A. Thouas, "Metallic implant biomaterials," Materials Science and Engineering R: Reports, vol. 87, pp. 1-57, 2015.

[17] D. Choudhury, J. M. Lackner, L. Major et al., "Improved wear resistance of functional diamond like carbon coated Ti-6Al-4V alloys in an edge loading conditions," Journal of the Mechanical Behavior of Biomedical Materials, vol. 59, pp. 586-595, 2016.

[18] B. Rahmati, A. A. D. Sarhan, W. J. Basirun, and W. A. B. W. Abas, "Ceramic tantalum oxide thin film coating to enhance the corrosion and wear characteristics of Ti-6Al-4V alloy," Journal of Alloys and Compounds, vol. 676, pp. 369-376, 2016.

[19] Q. Zhao, M. Chen, R. He, Z. Zhang, and M. A. Ashraf, "Review on antibacterial characteristics of bridge engineering biomaterials," Saudi Journal of Biological Sciences, vol. 23, no. 1, pp. S137-S141, 2016.

[20] A. Mahapatro, "Bio-functional nano-coatings on metallic biomaterials," Materials Science and Engineering C, vol. 55, pp. 227251, 2015.

[21] H. Matsuno, A. Yokoyama, F. Watari, M. Uo, and T. Kawasaki, "Biocompatibility and osteogenesis of refractory metal implants, titanium, hafnium, niobium, tantalum and rhenium," Biomaterials, vol. 22, no. 11, pp. 1253-1262, 2001.

[22] Y. X. Leng, H. Sun, P. Yang et al., "Biomedical properties of tantalum nitride films synthesized by reactive magnetron sputtering," Thin Solid Films, vol. 398-399, pp. 471-475, 2001. 
[23] P. S. Nnamchi, C. S. Obayi, I. Todd, and M. W. Rainforth, "Mechanical and electrochemical characterisation of new TiMo-Nb-Zr alloys for biomedical applications," Journal of the Mechanical Behavior of Biomedical Materials, vol. 60, pp. 68-77, 2016.

[24] J. Xu, W. Hu, Z.-H. Xie, and P. Munroe, "Reactive-sputterdeposited $\beta$-Ta2O5 and $\mathrm{TaON}$ nanoceramic coatings on $\mathrm{Ti}$ $6 \mathrm{Al}-4 \mathrm{~V}$ alloy against wear and corrosion damage," Surface and Coatings Technology, vol. 296, pp. 171-184, 2016.

[25] Y. Li, T. Zhao, S. Wei, Y. Xiang, and H. Chen, "Effect of $\mathrm{Ta} 2 \mathrm{O} 5 / \mathrm{TiO} 2$ thin film on mechanical properties, corrosion and cell behavior of the NiTi alloy implanted with tantalum," Materials Science and Engineering C, vol. 30, no. 8, pp. 12271235, 2010.

[26] F. Marco, F. Milena, G. Gianluca, and O. Vittoria, "Peri-implant osteogenesis in health and osteoporosis," Micron, vol. 36, no. 78, pp. 630-644, 2005.

[27] P. Stenlund, O. Omar, U. Brohede et al., "Bone response to a novel Ti-Ta-Nb-Zr alloy," Acta Biomaterialia, vol. 20, pp. 165175, 2015.

[28] J. Marciniak, J. Szewczenko, and W. Kajzer, "Surface modification of implants for bone surgery," Archives of Metallurgy and Materials, vol. 60, no. 3B, pp. 2123-2129, 2015.

[29] H. Liu, Y. Leng, and N. Huang, "Corrosion resistance of TiO film modified 316L stainless steel coronary stents in vitro," Journal of Materials Engineering and Performance, vol. 21, no. 3, pp. 424-428, 2012.

[30] M. Guo, A. Toloei, and H. H. Rotermund, "The effect of surface patterning on corrosion resistance of biomedical devices," Journal of Materials Engineering and Performance, vol. 25, no. 10, pp. 4190-4198, 2016.

[31] M. Basiaga, R. Jendruś, W. Walke, Z. Paszenda, M. Kaczmarek, and M. Popczyk, "Influence of Surface Modification on Properties of Stainless Steel Used for Implants / Wpływ Modyfikacji Powierzchni Na Właściwości Stali Nierdzewnej Stosowanej Na Implanty," Archives of Metallurgy and Materials, vol. 60, no. 4, 2015.

[32] H. Lasfargues, T. Glechner, C. Koller et al., "Non-reactively sputtered ultra-high temperature Hf-C and Ta-C coatings," Surface and Coatings Technology, vol. 309, pp. 436-444, 2017.

[33] W. Shuo, Z. Kan, A. Tao et al., "Structure, mechanical and tribological properties of $\mathrm{HfC}_{x}$ films deposited by reactive magnetron sputtering," Applied Surface Science, vol. 327, pp. 6876, 2015.

[34] O. Y. Khyzhun, "XPS, XES, and XAS studies of the electronic structure of substoichiometric cubic TaCx and hexagonal Ta2Cy carbides," Journal of Alloys and Compounds, vol. 259, no. 1-2, pp. 47-58, 1997.

[35] L. Reclaru, H. Lüthy, P.-Y. Eschler, A. Blatter, and C. Susz, "Corrosion behaviour of cobalt-chromium dental alloys doped with precious metals," Biomaterials, vol. 26, no. 21, pp. 43584365, 2005.

[36] D. Ferro, J. V. Rau, V. Rossi Albertini, A. Generosi, R. Teghil, and S. M. Barinov, "Pulsed laser deposited hard TiC, ZrC, HfC and $\mathrm{TaC}$ films on titanium: hardness and an energy-dispersive X-ray diffraction study," Surface and Coatings Technology, vol. 202, no. 8, pp. 1455-1461, 2008. 

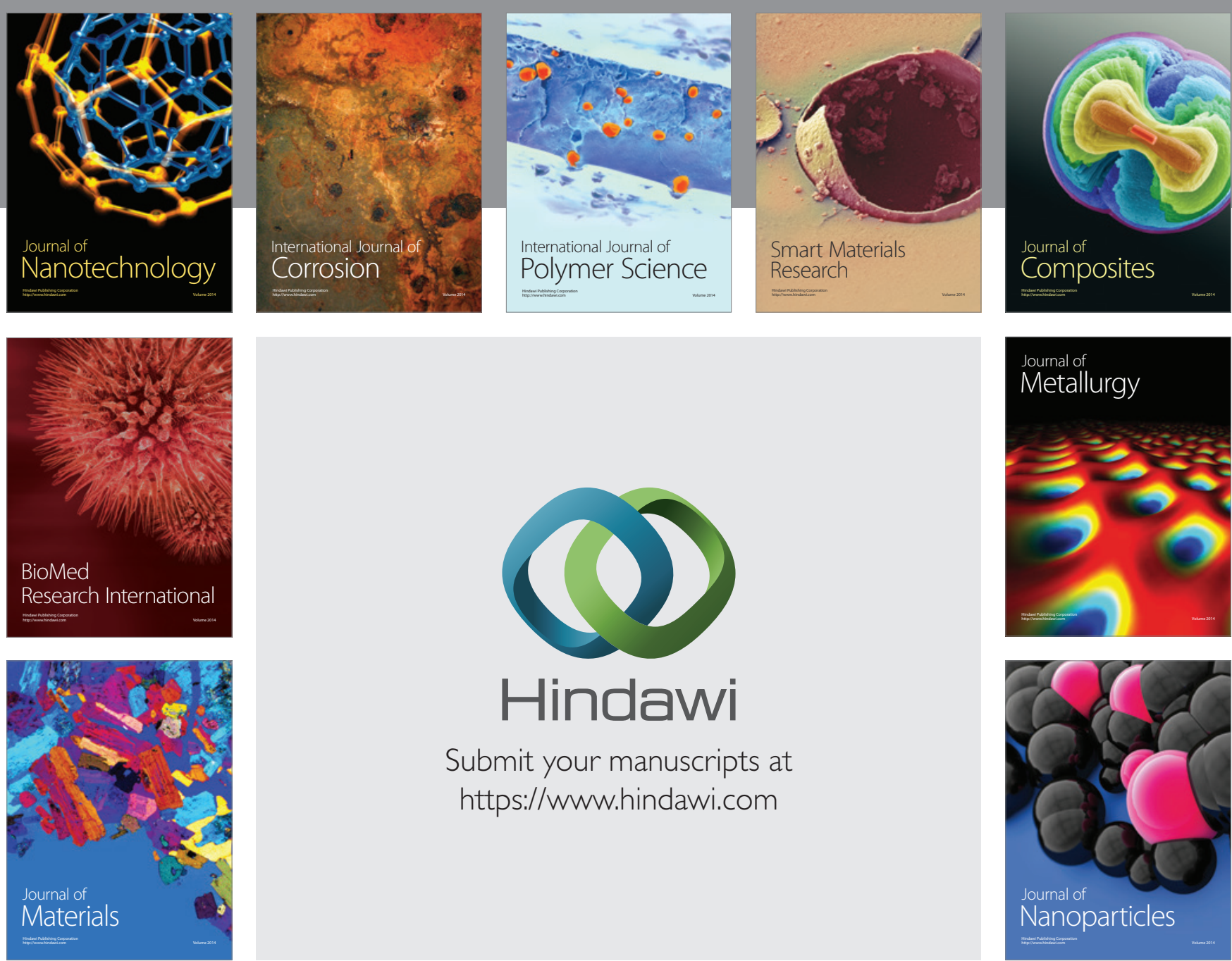

\section{Hindawi}

Submit your manuscripts at

https://www.hindawi.com

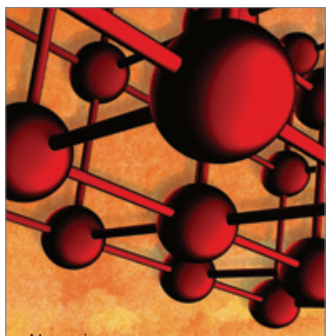

Materials Science and Engineering
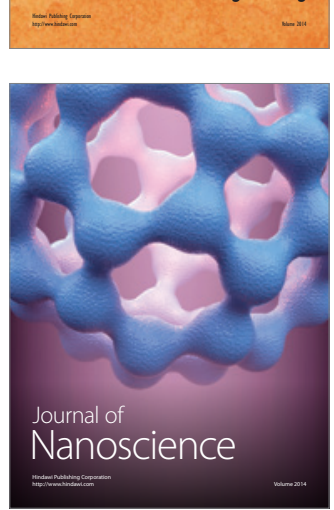
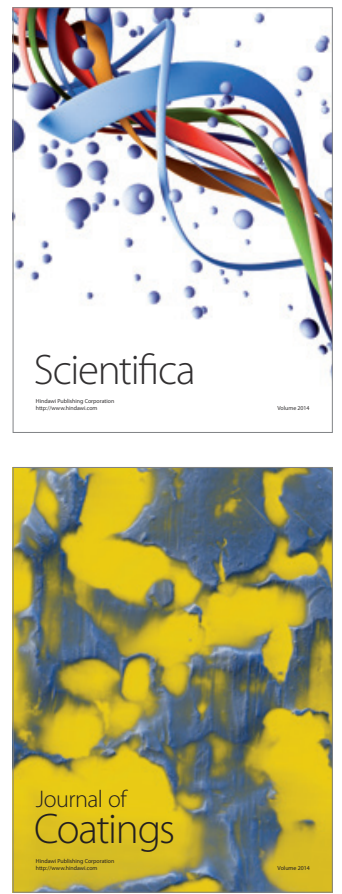
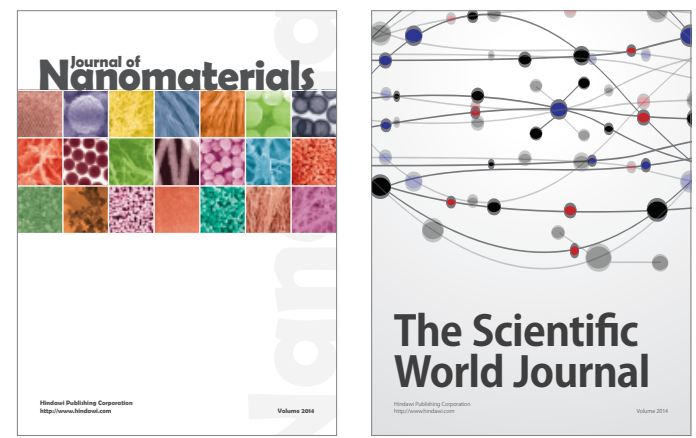

The Scientific World Journal
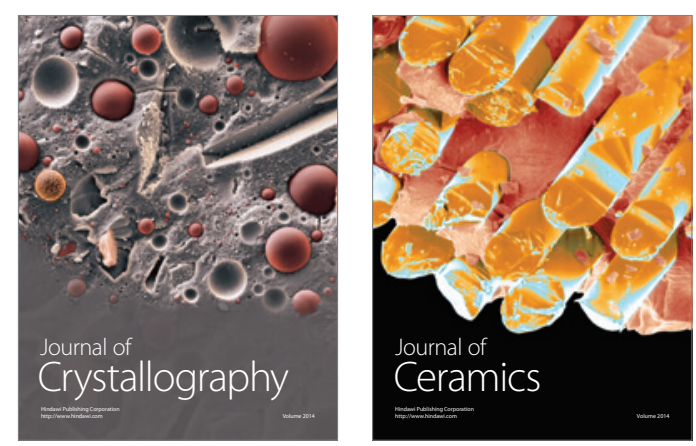
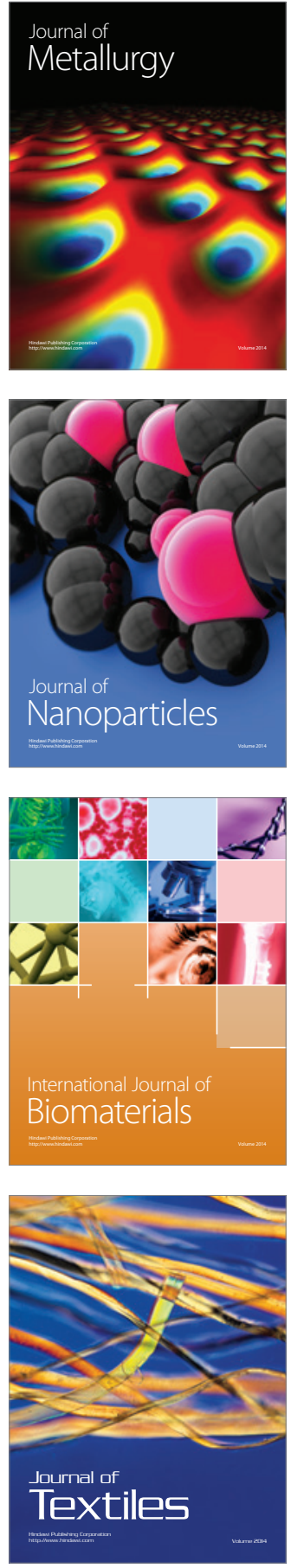